\title{
3D Raman imaging of multiphase fluid and melt inclusions: challenges and perspectives
}

\author{
LÁSZLÓ ELŐD ARADI ${ }^{1}$, TAMÁS SPRÁNITZ ${ }^{1}$, TIBOR \\ GUZMICS $^{1}$, CSABA SZABÓ ${ }^{2}$ AND MÁRTA BERKESI ${ }^{1}$ \\ ${ }^{1}$ Lithosphere Fluid Research Lab, Eötvös University \\ ${ }^{2}$ Eötvös University \\ Presenting Author: aradi.laszloelod@gmail.com
}

Fluids (including melts) play a crucial role in most geological processes from ore formation, through subduction and magmatism. Therefore, characterizing the fluids and/or melts, commonly found as inclusions of minerals, help to better understand these geological processes.

Fluid and melt inclusions from the Cabo Ortegal Complex (NW Spain) are derived from subduction zone conditions, generally showing great complexity in compositions of the constituent solid and vapor phases at room temperature [1].

To better understand multiphase (solid + liquid + vapor) inclusions, we aim to elaborate the methodological background of confocal 3D Raman microspectroscopic imaging of fluid and melt inclusions, which allows the collection of volumetric data of inclusions in $3 \mathrm{D}$. We are going to demonstrate how different parameters, such as the size of the confocal hole and the step size can be optimized in case of 3D Raman imaging in different host minerals under varying operation conditions. Raman 3D imaging on the inclusions, combined with FIB-SEM analyses of the exposed inclusions (e.g. EDS during FIB exposure), allows to carry out mass balance calculations by considering the volume percentages and the composition of each phase. In addition, uncertainty of volume percentages of solid phases obtained from Raman 3D imaging can be independently compared to complementary FIB-SEM data, optimizing our methodology.

The major goal of our study is to determine the compositions of primary fluid/melt inclusions, which could have been trapped as a suspected homogeneous phase based on our current observations, and to reconstruct phase transformation after entrapment, since they cannot be homogenized with regularly used microthermometric measurements. This study presents 3D reconstruction of inclusions via hyperspectral imaging using Raman spectroscopy compiled with FIB-SEM analyses. The results of our study could yield valuable contributions to the chemistry and nature of fluid and/or melt systems present in subduction zones.

This research was supported by the NRDIO_FK research fund nr. 132418.

[1] Spránitz et al. (2021) Goldschmidt Abstract, 04b 